Old Dominion University

ODU Digital Commons

Biological Sciences Faculty Publications

Biological Sciences

2001

\title{
Identification of a Defensin from the Hemolymph of the American Dog Tick, Dermacentor variabilis
}

Robert Johns

Daniel E. Sonenshine

Old Dominion University, dsonensh@odu.edu

Wayne L. Hynes

Old Dominion University

Follow this and additional works at: https://digitalcommons.odu.edu/biology_fac_pubs

Part of the Biology Commons, Entomology Commons, and the Parasitology Commons

\section{Repository Citation}

Johns, Robert; Sonenshine, Daniel E.; and Hynes, Wayne L., "Identification of a Defensin from the Hemolymph of the American Dog Tick, Dermacentor variabilis" (2001). Biological Sciences Faculty Publications. 73.

https://digitalcommons.odu.edu/biology_fac_pubs/73 


\title{
Identification of a defensin from the hemolymph of the American dog tick, Dermacentor variabilis
}

\author{
Robert Johns, Daniel E. Sonenshine", and Wayne L. Hynes
}

Department of Biological Sciences, Old Dominion University, Norfolk, Virginia 23529, USA

* Corresponding author:

Dr. Daniel E. Sonenshine

Department of Biological Sciences

Old Dominion University

Norfolk, Virginia 23529

Tel: (757) 683 - 3612; Fax (757) 683 - 5283

E-mail: dsonensh@odu.edu 
Abstract.

Hemolymph from partially fed virgin $D$. variabilis females was collected following $B$. burgdorferi challenge and assayed for antimicrobial activity against Bacillus subtilis and the Borrelia burgdorferi. A small inducible cationic peptide was identified by SDS-PAGE in the hemolymph of these ticks as early as $1 \mathrm{~h}$ post-challenge. Following purification by a three step procedure involving sequential SepPak elution, reversed phase high performance liquid chromatography (RP-HPLC) and gel electrophoresis, the yield of the active peptide was approximately $0.1 \%$ of the total protein in the hemolymph plasma. The molecular weight, 4.2 $\mathrm{kDa}$, was determined by MALDI-TOF mass spectrometry. $\mathrm{N}$-terminal sequencing by the Edman degradation method gave a sequence for the first 30 amino acids as: G-F-G-C-P-L-N-Q-G-A-CH-N-H-C-R-S-I-(R)-(R)-(R)-G-G-Y-C-S-Q-I-I-K. A computer search of databases showed that the peptide had $83 \%$ similarity to a defensin found in a scorpion. This is the first report of a defensin from a tick, termed varisin to indicate its unique origin. The peptide was stable at least up to $70^{\circ} \mathrm{C}$. Although the tick defensin alone was not immediately effective against $B$. burgdorferi, tick defensin plus lysozyme killed more $65 \%$ of cultured $B$. burgdorferi within $1 \mathrm{~h}$.

Keywords. Defensin, antimicrobial peptide, hemolymph, Dermacentor variabilis, Ixodes scapularis. 


\section{Introduction.}

Ticks transmit a greater variety of infectious microorganisms to vertebrates than any other group of hematophagous arthropods (Sonenshine, 1993). However, they are able to eliminate infection with non vector-transmitted microbes, e.g., Bacillus subtilis or Escherischia coli (Johns et al.1998, 2000a, b; Kovár 'et al.2000; Kopácek et al. 1999; Kryuchechnikov, 1991; Kühn and Haug, 1994). If ticks, like other invertebrates, have an immune system, how are they able to harbor the numerous infectious microbes that live in their tissues without demonstrable injury? Aside from brief reports of hemolymph lysozyme (Kühn and Haug, 1994; Podboronov, 1991), lectins (Grubhoffer et al., 1991) and the evidence for unspecified peptides (Johns et al. 1998; 2000a), no information is available concerning antimicrobial proteins in tick hemolymph, whether they are inducible or constitutive, or whether there are bacterial group-specific antimicrobial proteins. How the bacteria survive in the presence of these immune challenges, how long they survive, the percentage of surviving bacteria that invade nearby tick organs and other aspects of the dynamics of spirochete passage in the ticks has received little attention. Phagocytosis of invading Borrelia burgdorferi has been reported in the deer tick, Ixodes scapularis (Coleman et al., 1997) but no evidence of bacteriolysis has been reported.

In the American dog tick, Dermacentor variabilis, introduction of bacteria into the hemocoel provokes a robust antimicrobial response, such that most species of bacteria are destroyed within a few hours or less (Johns et al. 2000a, b). When challenged with B. burgdorferi, the spirochetes are lysed in $<1 \mathrm{~h}$. In addition, a small $(\sim 5.3 \mathrm{kDa})$ peptide was reported to be induced (Johns et al. 2000a). These findings suggest the presence of a small peptide, perhaps capable of lysing bacteria alone or in concert with lysozyme (Kühn and Haug, 1994; Kopáček et al.1999). 
The current study was done to determine the identity and characteristics of the inducible peptide observed in a tick and ascertain whether it may contribute to the tick's ability to control invading microbes. In this paper, we report the finding of a defensin in the hemolymph of the American dog tick, D. variabilis, the first such peptide reported from a tick.

\section{MATERIALS AND METHODS}

\subsection{Ticks.}

D. variabilis ticks were colonized as described by Johns et al. (1998) using rats (Rattus norvegicus) and rabbits (Oryctolagus cunniculus). ${ }^{1}$ I. scapularis were colonized from wild-caught adult ticks collected near Armonk, New York. The adults were fed on rabbits and the spirochete-free progeny reared to adults. All life stages were fed on rabbits. Fed ticks of both species were incubated in an AMINCO-AIRE incubator (Black Mountain, NC) at $26^{\circ} \mathrm{C} \pm 1{ }^{\circ} \mathrm{C}$ and $92 \pm 1 \% \mathrm{RH}$.

\subsection{Bacteria.}

The B. burgdorferi low passage B31 strain used in this study was provided by Center for Disease Control, Fort Collins, Co. Aliquots were removed and subcultured in BSK-H media (Sigma, St. Louis, $\mathrm{MO}$ ) at $33^{\circ} \mathrm{C}$ in a $5 \% \mathrm{CO}_{2}$ incubator. To maintain their low passage state, cultures were subcultured no more than 5 times. Bacterial suspensions for all assays were made by centrifuging cells at $3000 \times \mathrm{g}$ for $10 \mathrm{~min}$, washing the pellet with $0.2 \mathrm{M}$ Phosphate-buffered saline (PBS) pH 7.4, and resuspending in the same buffer. Bacillus subtilis (ATCC strain 6051) was obtained from the American Type Culture Collection. Bacillus cultures were grown (18 hrs) in tryptic-soy broth (TSB), pelleted by centrifugation at $16,000 \times \mathrm{g}$ and resuspended in Shen's tick bleeding buffer (TBB) (Oliver et al. 1974). The bacterial suspensions (both B. burgdorferi 
and B. subtilis) were counted using a Brightline hemacytometer (Hausser, Hoarsham, PA), observed by phase contrast with a Nikon Optiphot compound microscope, and the cell numbers adjusted as required for the experiments.

\subsection{Tick inoculations and hemolymph collections.}

All tick inoculations with $B$. burgdorferi or $B$. subtilis were done as described by Johns et al. (1998). Briefly, $15,000-20,000$ bacterial cells in a $5 \mu l$ PBS (pH 7.4) suspension were injected into the hemocoel cavity of partially fed virgin female $D$. variabilis via the foramen between the capitulum and the anterior end of the scutum. A $50 \mu l$ Hamilton syringe (Hamilton, Reno, NV) with a 30-gauge hypodermic needle was used for the bacterial inoculations.

Hemolymph was collected by severing the forelegs at the coxal-trochanteral joint, applying gentle pressure on the tick's body and drawing the clear liquid expressed into a glass micropipette. Hemolymph was diluted 1:1 in ice cold TBB containing 2 mM Phenylmethylsulfonyl Fluoride (PMSF) (Sigma). Then, the sample was centrifuged at 3,000 x g for $10 \mathrm{~min}$, the supernatant (plasma portion) was retained and stored at $-80^{\circ} \mathrm{C}$ until used for assay.

\subsection{Protein Determinations.}

The amount of protein in the samples was determined using either the BioRad Protein assay kit (BioRad, Richmond, Va.) or the BCA Protein assay Reagent (Pierce, Rockford, II) according to the manufacturer's instructions.

\subsection{Microtiter well inhibition assays.}

Whole tick hemolymph plasma collected at $1 \mathrm{~h}$ post inoculation from $B$. burgdorferi infected ticks or sham inoculated (non-infected) ticks was assayed for anti-B. subtilis and anti-B.

\footnotetext{
${ }^{1}$ All use of animals in this research was done in accordance with protocols approved by the Old Dominion University Institutional Animal Use and Care Committee Protocols 98-034 and 98-
} 
burgdorferi activity. Antimicrobial activity was assessed in a 96 well microtiter plate (Corning, Corning, NY). Fifty $\mu$ l of a $3-5 \mathrm{~d}$ B. burgdorferi culture (adjusted to $4.5 \times 10^{3}$ cells per $\mu \mathrm{l}$ ) was added to wells containing $10 \mu \mathrm{l}$ of tick hemolymph plasma sample. For antimicrobial activity against $B$. subtilus, cultures were grown overnight in TSB, diluted 1:30, incubated $3 \mathrm{~h}$ and further diluted 5 fold prior to use in the assay. To each well, $25 \mu$ of $B$. subtilis culture was added and the plates incubated at $37^{\circ} \mathrm{C}$ overnight. Controls were done with wells containing bacteria and TSB and PBS but no hemolymph fractions. Samples were evaluated visually for absence of or reduction in bacterial growth.

\subsection{Protein Purification.}

To obtain the material needed for amino acid sequence determination, the peptide was isolated by means of a 3-step procedure using Waters ${ }^{\mathrm{TM}}$ Sep-Pak@ $\mathrm{C}_{18}$ cartridges (Milford, MA), reversed phase high performance liquid chromatography (RP-HPLC) and gel electrophoresis. The SepPaks were conditioned first with HPLC grade methanol (J. T. Baker, Phillipsburg, NJ) and then with distilled water, $15 \%$ acetonitrile $/ 0.1 \%$ trifluoroacetic acid (TFA) and finally with $0.1 \%$ TFA. Following conditioning, crude $D$. variabilis hemolymph plasma was diluted 2-fold with tick saline, (adjusted to $\mathrm{pH} 3.5$ ) and loaded onto the cartridge. Next, the cartridges were eluted sequentially with $3 \mathrm{ml}$ each of $0.1 \%$ TFA, $15 \%$ acetonitrile/ $0.1 \%$ TFA, $60 \%$ acetonitrile/ $0.1 \%$ TFA and $100 \%$ acetonitrile at a elution flow rate of $0.5 \mathrm{ml} / \mathrm{min}$. Eluates were collected on ice and concentrated to dryness using a Centrivap vacuum evaporator (Labconco Corporation, Kansas City, MO). Samples were reconstituted in $50 \mathrm{mM}$ PBS, $\mathrm{pH} 5.7$, and stored at $-80^{\circ} \mathrm{C}$. Aliquots were tested for antimicrobial activity by the microtiter inhibition assay and their protein profiles analyzed by SDSPAGE. Further purification of the SepPak eluates with the greatest antimicrobial activity was done 
using a Waters HPLC system (Waters, Milford, MA) and a Vydac $\mathrm{C}_{4}$ RP narrow bore (2.1 mm I.D.) column (Nest Group, Southborough, MA). The solvent was a mixture of water with $0.1 \%$ trifluoroacetic acid (TFA) and acetonitrile (ACN). The gradient was from $70 \%$ water $(0.1 \% \mathrm{TFA})$ : $30 \%$ acetonitrile to $30 \%$ water ( $0.1 \%$ TFA): $70 \%$ acetonitrile over 60 min. Peaks were detected with a Shimadzu photodiode array detector (Shimadzu, Columbia, MD) set in the UV range from 210 to 350 $\mathrm{nm}$. Fractions were collected on ice, dried in the vacuum evaporator, then reconstituted in $50 \mathrm{mM}$ PBS and tested for antimicrobial activity. The fraction with the greatest antimicrobial activity was further purified using a Vydac $C_{18} R P$ analytical column (4.1 mm I.D. $\times 250 \mathrm{~mm}$ long) and the same solvents and gradient system as described above. Final purification was by gel electrophoresis (SDSPAGE) and staining with Coomassie Blue R stain (Sigma).

\subsection{Gel electrophoresis.}

Sodium dodecyl sulfate-polyacrylamide gel electrophoresis (SDS-PAGE) was based on the method of Laemmli (1970) using a Pharmacia Biotech Model SE 260-10A vertical minigel system (Pharmacia, Biotech, Piscataway, NJ) and 10-20\% precast Tricine gradient gels (Novex-Invitrogen, San Diego, CA). Hemolymph plasma samples from B. burgdorferi -challenged ticks or shaminoculated controls were collected at 1,6 and $18 \mathrm{~h}$ post-inoculation. Approximately $170 \mu \mathrm{g}$ of hemolymph protein per sample from $D$. variabilis was loaded into each lane of the gel and electrophoresed according to the manufacturer's instructions. For analysis of the relative molecular weights (rMW) and protein concentrations, gels were stained by the silver stain method (Invitrogen, San Diego, CA) carried out in accordance with the manufactuer's instructions. Stained gels were photographed with the Kodak DC120 Digital Camera (Kodak, Rochester, NY). Tentative protein molecular weight assignments were done using the Kodak ID Software. ${ }^{\mathrm{TM}}$ 


\subsection{Amino acid sequence determination and molecular weight.}

N-terminal amino acid sequence determination was done by Edman degradation (Commonwealth Biotechnologies, Richmond, VA, USA and The Biomolecular Research Facility, University of Virignia, Charlottesville, VA) on a protein band excised and eluted from the stained electrophoresis gel. Molecular weight determination was done on an aliquot of the HPLC-purified protein sample by MALDI-TOF mass spectrometry (Biomedical Mass Spectrometry Laboratory, University of Virginia, Charlottesville, VA, USA).

\subsection{Heat stability assay.}

To assess the heat stability of the putative tick defensin, $10 \mu l$ aliquots of HPLC-purified samples containing this peptide (ca. $20 \mu \mathrm{g}$ ) were placed in microcentrifuge tubes and heated for 1 hour. The temperature range consisted of room temperature $\sim 25,30,40,50,60$, and $70^{\circ} \mathrm{C}$. Next, the heat-treated samples were pipetted into 3-mm wells on a TSA plate and seeded with $B$. subtilis as described by Johns et al. $(2000 \mathrm{c})$. Following incubation at $37^{\circ} \mathrm{C}$ overnight, the bacterial lawn was inspected for zones of inhibition. Zone diameters were measured $(\mathrm{mm})$ and recorded.

\subsection{Borrelia inhibition assay.}

To assess the ability of the tick defensin to inhibit $B$. burgdorferi, $10 \mu$ aliquots of HPLC-purified hemolymph samples containing the tick defensin or egg white lysozyme (Sigma) was added to wells of a microtiter well plate containing $200 \mu l$ of $B$. burgdorferi cultures (approximately $4.5 \times 10^{3}$ spirochetes/ $\mu$ l) in BSK-H. To assess possible synergistic effects with lysozyme, $1.0 \mu \mathrm{g}$ of lysozyme was added to the cultures along with the tick defensin. Borrelia numbers were recorded at $1 \mathrm{~h}$ and $24 \mathrm{~h}$. Reduction in the numbers of total cells counted in the treated samples versus the control was considered as inhibition, which was expressed as a percentage of the numbers present in the control (with B. burgdorferi alone). 


\section{Results}

\subsection{Evidence for the existence of a defensin-like peptide in ticks.}

Hemolymph from $D$. variabilis females challenged by inoculation with $B$. burgdorferi was found to be strongly inhibitory for these bacteria when tested in microtiter well plates. Serial dilutions of the crude hemolymph plasma showed anti-B. subtilis activity to an 8-fold dilution (Table 1 a). When hemolymph plasma from these ticks was examined by SDS-PAGE, two unique peptide bands were observed in the samples from ticks challenged with B. burgdorferi, but not in the samples from the sham-inoculated controls (Fig. 1). These peptides had approximate molecular weights of 4 and 5 $\mathrm{kDa}$, respectively. They were most strongly expressed within $1 \mathrm{~h}$ post-challenge. By $6 \mathrm{~h}$ or $18 \mathrm{~h}$ postchallenge, these peptides were barely detectable and there was little apparent difference in the protein profiles at these time intervals and the sham-inoculated controls. A protein band that co-migrated (approximately) with lysozyme showed greatly increased expression at $1 \mathrm{~h}$ post-challenge, less so at 6 and $18 \mathrm{~h}$, when compared to the sham-inoculated control (Fig. 1). Finally, there was almost no mortality when $D$. variabilis females were inoculated with either $B$. subtilis $(2.1 \%, \mathrm{n}=57)$ or $B$. burgdorferi $(0 \%, \mathrm{n}=18)$ during a 5-day incubation period. None of the sham-inoculated ticks died $(n=42)$.

\section{Purification of the putative defensin from $D$. variabilis hemolymph}

Fractionation of hemolymph from $B$. burgdorferi-challenged females through $\mathrm{C}_{18}$ SepPaks using 0.2M PBS and increasing strength acetonitrile solutions did not elute the tick defensin efficiently. Weak inhibition was observed when the eluates were tested against $B$. subtilis in the microtiter well inhibition test (Table 1A) and no evidence of the putative defensin was observed when the samples were separated by SDS-PAGE (Fig. 2). Note that the lanes for the $15 \%$ and $60 \%$ acetonitrile/ $0.2 \mathrm{M}$ PBS were devoid of any evidence of this peptide band. However, when $0.1 \%$ TFA was used instead 
of PBS, the putative defensin and other small peptide bands were detected in both the $15 \%$ and $60 \%$ acetonitrile/0.1\% TFA eluates (Fig. 2). A total of $85 \mathrm{mg}$ of hemolymph plasma was fractionated by the latter method, with a protein yield of $21 \mathrm{mg}$ in the $15 \%$ fraction and $6 \mathrm{mg}$ in the $60 \%$ acetonitrile fraction. The titer of the two fractions was $1: 32$ and 1:16, respectively. When considered on the basis of protein content (titer/mg protein), the $15 \%$ fraction showed a titer of $1.5 / \mu \mathrm{g}$ protein, whereas the $60 \%$ fraction showed a titer of $3.6 / \mu \mathrm{g}$ protein (Table $1 \mathrm{~A}$ ). For the $60 \%$ fraction, the fraction of greatest interest, this represents a 19.9 fold level of purification (Table 1B).

The $60 \%$ acetonitrile eluates from the SepPak fractionation were pooled and further purified by RP-HPLC using a narrow bore $\mathrm{C}_{4}$ column. Two $1 \mathrm{~min}$ fractions collected at 5 and $7 \mathrm{~min}$ after the sample was injected showed antimicrobial activity against $B$. subtilis when assayed on agar plates (10 and $12 \mathrm{~mm}$ zones of inhibition, respectively). The HPLC chromatogram showed several peaks (Fig. 3), including a peak at $7 \mathrm{~min}$, which corresponded to the fraction showing the largest zone of bacterial inhibition. SDS-PAGE of these fractions showed a $\sim 5-\mathrm{kDa}$ band, as well as at least 4 other higher molecular weight bands (data not shown). The protein content of the 7-minute fraction was estimated at $2.3 \mathrm{mg}$. Anti-B. subtilis activity in microtiter well tests showed that the fraction had activity at a 1:16 fold dilution. This represents an approximately 32-fold level of purification (Table 1B). Further purification was done by RP-HPLC with a $\mathrm{C}_{18}$ column. Antimicrobial activity against B. subtilis was found in a single peak collected at $17.0 \mathrm{~min}$ after injection (Fig. 4). When analyzed by SDS-PAGE, this fraction contained the $5 \mathrm{kDa}$ band and a barely detectable band at $\sim 10 \mathrm{kDa}$ (Fig. 5). Three $1 \mathrm{~min}$ fractions collected from the HPLC column immediately before, at and after peak detection indicated antimicrobial activity only in the fraction coincident with the 17.0 min peak, i.e., the fraction in which the 5-kDa peptide was most abundant. This fraction had a total protein content of $0.19 \mathrm{mg}$. It was active against $B$. subtilis in the microtiter well inhibition test to a dilution of up to 
1:32, with an average titer of 26.6. This represents a 619-fold level of purification (Table 1B), representing approximately $0.1 \%$ of the total protein content of the hemolymph plasma from the challenged ticks. When examined by SDS-PAGE, the HPLC fraction appeared to be highly purified, with the $\sim 5 \mathrm{kDa}$ as the only major band present. Consequently, an aliquot of this fraction was submitted for molecular weight determination, and a gel slice containing the peptide excised from the PAGE gel was submitted for amino acid sequence determination.

\subsection{Molecular characterization of the tick defensin.}

MALDI-TOF done with the $\mathrm{C}_{18}$ fraction collected from the HPLC showed a single dominant peak with a molecular mass of 4,229 daltons, representing approximately $95 \%$ of the protein in the sample, and two very small peaks with masses of 4,615 and 9218 daltons (Fig. 6). Since the HPLC fraction was not absolutely pure, amino acid sequence determination was done on the band excised and eluted from the SDS-PAGE gel. N-terminal sequencing by the Edman degradation method gave a sequence for the first 30 amino acids as: G-F-G-C-P-L-N-Q-G-A-C-H-N-H-C-R-S-I-(R)-(R)-(R)-G-G-Y-C-SQ-I-I-K. The amino acids in positions $19-21$ (noted in parentheses) were identified tentatively as arginine, since it was the only amino acid that increased even though the amount was very small. A computer database search showed that the peptide had $83 \%$ similiarity (identities $25 / 30$ ) to a defensin found in a scorpion. We have named this tick defensin varisin to indicate that it is produced by $D$. variabilis.

\subsection{Thermostability of the tick defensin.}

Examination of the zones of inhibition around the wells of the agar plate containing the heattreated HPLC fractions showed antimicrobial activity against $B$. subtilis for a temperature range from $25-70^{\circ} \mathrm{C}$. Notably, the zones of inhibition were greater for samples treated at the higher temperatures, from $40-70^{\circ} \mathrm{C}$, than at the lower temperatures (Fig. 7). 


\subsection{Anti-Borrelia activity of the tick defensin.}

When tested against $B$. burgdorferi, the HPLC $\left(\mathrm{C}_{18}\right)$ purified defensin fraction showed little inhibitory activity against the spirochetes within $1 \mathrm{~h}(2.1 \% \pm 1.8 \%$ inhibition), although this increased to $45 \pm 5.6 \%$ by $24 \mathrm{~h}$. In contrast, addition of lysozyme dramatically increased inhibitory activity to $66 \pm 5.2 \%$ within $1 \mathrm{~h}$, but did it not increase further, remaining at $63 \pm 4.4 \%$ after $24 \mathrm{~h}$. (Fig. 8).

\section{Discussion}

Defensins are widespread throughout the animal kingdom, both in vertebrates and invertebrates. On exposure to bacterial challenge, they are induced rapidly and exhibit bacteriocidal/bacteriostatic activity against numerous bacteria (Gillespie et al., 1997; Beerntsen et al., 2000; Cociancich et al., 1994; Hoffman and Hetru, 1992; Lowenberger et al., 1995). Defensins are mostly small peptides (ca. $4 \mathrm{Kda}$ ), usually containing 6 cysteine residues. These peptides attack primarily gram-positive bacteria, leading to cell lysis by the formation of membrane penetrating channels (Gillespie et al.1997) or intramolecular bridges (Beerntsen et al. 2000). In arthropods, defensins have been reported most frequently from the hemolymph, but can also occur in the midgut, e.g., in the mosquito where they are activated by Plasmodium ookinetes (Richman et al.1997). Defensins are extremely potent; Hoffman and Hetru (1992) reported that exposure of Micrococcus luteus for one minute to $0.5 \mu \mathrm{M}$ of the peptide killed all of the bacteria in their test sample.

This is the first report of a defensin isolated from a tick. Based on the molecular weight, 4229 daltons, the peptide may contain approximately $38-40$ amino acids. The sequence of the first 30 amino acids, G-F-G-C-P- L-N-Q-G-A-C-H-N-H-C-R-S-I-(R)-(R)-(R)-G-G-Y-C-S-Q-I-I-K, is similar 
to the defensins of other invertebrates. Greatest similarity, $83 \%$, was found with the defensin of a scorpion, Leiurus quinquestriatus (Cociancich et al.1993), which like the ticks is a member of the arthropod class Arachnida. The scorpion defensin shows a high degree of similarity to the defensin from dragonflies of the ancient order Odonata. Remarkably, it also shows homology (70\%) with the defensin from the Mediterranean mussel, Mytilus galloprovincialis with a molecular mass of 4418 and comprising 38 amino acids, including 8 cysteines (Hubert et al.1996). Such similarities suggest that this subclass of defensins is highly conserved. Moreover, these reports show that small defensins similar in size to the tick defensin have been reported from a variety of different arthropods (Gillespie et al. 1997). The only other report of a defensin from a chelicerate arthropod is that of tachylepsin from the tissues of horseshoe crabs (Kawabata et al. 1997). However, this novel (79 residues) defensin-like antimicrobial peptide also shows activity gram-negative as well as grampositive bacteria. Antimicrobial activity against gram positive bacteria and fungi was also found in the hemolymph and gut of the tick, Boophilus microplus, due to a fragment of alpha-hemoglobin, but this antimicrobial activity is the result of enzymatic digestion of host hemoglobin (Fogaca et al. 1999).

Most defensins are active only against gram positive bacteria (Gillespie et al.1997). Thus, it is of interest that the tick defensin also showed activity against $B$. burgdorferi, especially when combined with chicken lysozyme. In a previous study, Johns et al. (2000a) observed that cell-free hemolymph from Borrelia-challenged D. variabilis strongly inhibited B. burgdorferi (72\%) whereas hemolymph from sham-inoculated ticks had little effect (11\%). They also observed induction of a new peptide, ca. $5.3 \mathrm{kDa}$, now identified in the present study as the defensin varisin, as well as increased expression of a lysozyme-like peptide. However, without purification of the hemolymph antimicrobial peptides, they were unable to assess how tick defensin or lysozyme act to kill these 
spirochetes. Since lysozyme (chicken) is not borreliacidal by itself but lysozyme plus tick defensin kills most borreliae within $1 \mathrm{~h}$ (Fig. 8), we hypothesize that the ability of $D$. variabilis hemolymph to inhibit these bacteria may be due to a synergistic effect between these two peptides. Defensins and other small molecular weight antimicrobial peptides of insects have been shown to act as porins to open channels in the lipopolysaccharide layer of gram negative bacteria, thereby facilitating penetration of lysozyme and allowing for subsequent destruction of the bacteria (Gillespie et al. 1997).

In a separate study, Johns et al. (2000 c) noted that hemolymph from B. burgdorferi-challenged D. variabilis was strongly borreliacidal. Virtually all borreliae were lysed within $1 \mathrm{~h}$, leaving only scattered immunfluorescent fragments. In contrast, hemolymph from $B$. burgdorferi-challenged $I$. scapularis did not show any ability to inhibit the bacteria. These authors suggested that the lack of bacteriolysis allowed the spirochetes to survive in the hemolymph of I. scapularis (the natural vector of this disease agent) long enough to invade the salivary glands and other tissues. One possible explanation for the absence of lytic activity in I. scapularis may be that this species either lacks or does not express the defensin in response to challenge by these particular bacteria. However, further studies are needed to determine whether a defensin similar to varisin is expressed in I. scapularis when challenged with $B$. burgdorferi or other bacteria.

Differences in the expression of the tick defensin in the two different tick species, D. variabilis and I. scapularis may help to explain why only the latter is vector competent. However, to date we have examined only the hemolymph of $D$. variabilis. The midgut is another site where defensins may be active. In the mosquito midgut, defensins were activated by Plasmodium ookinetes (Richman et al. 1997). If defensin is expressed in the midgut of $D$. variabilis but not in I. scapularis, this may 
be another important factor in explaining the differences in vector competence between the two species.

\section{Acknowledgements}

We thank the Thomas F. Jeffress and Kate Miller Jeffress Memorial Trust and the Old Dominion University Eminent Scholars Fund for their support of the research reported in this paper. We also thank Dr. Martin E. Schriefer, Division of Vector-borne Diseases, Centers for Disease Control, Fort Collins, CO for the supply of the low passage B31 strain of Borrelia burgdorferi.

\section{References}

Beerntsen, B., James, A.A. and Christensen, B.M. 2000. Genetics of mosquito vector competence. Microbiol. Mol. Biol. Rev. 64: 115 - 137.

Cociancich, S., Bulet, P., Hetru, C. and Hoffman, J.A. 1994. The inducible antibacterial peptides of insects. Parasitology Today 10: 132 - 138.

Cociancich, S., Goyffon, M., Bontems, F., Bulet, P., Bouet, F., Menez, A, and Hoffman, J. 1993. Purification and characterization of a scorpion defensin, a $4 \mathrm{kDa}$ antibacterial peptide presenting structural similarities with insect defensins and scorpion toxins. Biochem. Biophys. Res. Commun. 194: 17-22.

Coleman, J.L., Gebbia, J.A., Piesman, J., Degen, J.L., Bugge, T.H. and Benach, J.L. 1997. Plasminogen is required for efficient dissemination of $B$. burgdorferi in ticks and for eenhancement of spirochetemia in mice. Cell 89: $1111-1119$.

Fogaca, A.C., da Silva, P.I., Jr., Miranda, M.T., Bianchi, A.G., Miranda, A., Ribolla, P.E. and Daffre, S. 1999. Antimicrobial activity of a bovine hemoglobin fragment in the tick, Boophilus microplus. J. Biol. Chem. 274: 25330-25334. 
Gillespie, J.P., Kanost, M.R. and Trenczek, T. 1997. Biological mediators of insect immunity. Annu. Rev. Entomol. 42: 611 - 643.

Grubhoffer, L., Vereš, J. and Dusbábek, F. 1991. Lectins as the molecular factors of recognition and defense reaction of ticks. In: Dusbábek, F. and Bukva, V. (Eds.) Modern Acarology 2: 381 - 388.

Hoffmann, J. A., and C. Hetru. 1992. Insect defensins: inducible antibacterial peptides. Immunology Today. 13: 411- 415 .

Hubert, F., Noel, T. and Roch, P. 1996. A member of the arthropod defensin family from edible Mediterranean mussels (Mytilus galloprovincialis). Eur. J. Biochem. 240: 302 - 306.

Johns, R., Sonenshine, D.E. and Hynes, W. 1998. Control of bacterial infections in the hard tick, Dermacentor variabilis (Say): evidence for the existence of antimicrobial proteins in tick hemolymph. J. Med. Entomol. 35: 458 - 464.

Johns, R., Sonenshine, D.E. and Hynes, W.L. 2000a. Responses Response of the tick, Dermacentor variabilis (Acari: Ixodidae) to hemocoelic inoculation of Borrelia burgdorferi (Spirochetales) J. Med. Entomol. 37: 265 - 270.

Johns, R. Sonenshine, D.E. and Hynes, W.L. 2000b. Tick immunity to microbial infections: antibacterial peptides or proteins in the hemolymph of the hard tick Dermacentor variabilis (Acari: Ixodidae). Proc. 10th Internatl. Congr. Acarol. Canberra, Australia (in press).

Johns, R. Onishi, J, Broadwater, A., Sonenshine, D.E., De Silva, A. and Hynes, W.L. 2000c. Contrasts in Tick Innate Immune Responses to Borrelia burgdorferi challenge: Immunotolerance in Ixodes scapularis versus immunocompetence in Dermacentor variabilis (Acari: Ixodidae). J. Med Entomol (in press). 
Kawabata, S., Saito, T., Saeki, K., Okino, N., Miautani, A., Toh, Y., and Iwanaga, S.1997. cDNA cloning, tissue distribution and subcellular localization of horseshoe crab big defensin. Biol. Chem. 378: 289 - 92.

Kopácek, P., Vogt, R., Jindrák, L., Weise, C. and Šafałik, I. 1999. Purification and characterization of the lysozyme from the soft tick, Ornithodoros moubata. Insect Biochem. Mol. Biol. 29: 989 997.

Kovár, V., Kopácek, P. and Grubhoffer, L. 2000. Isolation and characterization of Dorin M, a lectin from plasma of the soft tick, Ornithodoros moubata. Insect Biochem. Mol. Biol. 30: 195 - 205. Kryuchechnikov, V.N. 1991. Protective responses of Ixodoidea hemocytes. In: Dusbábek, F. and Bukva, V. (Eds.) Modern Acarology. 1: 331 - 334.

Kühn, K.H. and Haug, T. 1994. Ultrastructure, cytochemical and immunocytochemical characterization of hemocytes of the hard tick Ixodes ricinus (Acari: Chelicerata). Cell Tissue Res. 277: 493 - 504.

Laemmli, U.K. 1970. Cleavage of structural proteins during the assembly of the head of bacteriophage $T_{4}$. Nature (London) 227: 680 - 685.

Lowenberger, C., Bulet, P., Charlet, M., Hetru, C., Hodgeman, B., Christensen, B.M. and Hoffman, J.A. 1995. Insect immunity: Isolation of three novel inducible antimicrobial defensins from the vector mosquito, Aedes aegypti. Insect Biochem. Mol. Biol. 25: 867-873.

Oliver, J.H., Jr., Wilkinson, P.R. and Kohls, G.M. 1974. Observations on hybridization of three species of North American Dermacentor ticks. Journal of Parasitology 58: 380 - 84.

Podboronov, V.M. 1991. Antibacterial protective mechanisms of ixodid ticks. In: Dusbábek, F. and Bukva, V. (Eds.) Modern Acarology 2: 375 - 380. 
Richman, A.M., Dimopoulos, G., Deelye, D. and Kafatos, F.C. 1997. Plasmodium activates the innate response of Anopheles gambiae mosquitoes. EMBO J. 16: $6114-6119$.

Sonenshine, D.E. 1993. Biology of Ticks. Oxford University Press, New York. 447 pp.

\section{Figure Legends}

Fig 1. SDS-PAGE of hemolymph from Dermacentor variabilis fed virgin females collected at different intervals after challenge with Borrelia burgdorferi. Lane 1, molecular weight standards; lane 2, $1 \mathrm{~h}$; lane $3,6 \mathrm{~h}$; lane 4, $18 \mathrm{~h}$; lane 5, sham-inoculated control $(1 \mathrm{~h})$. Arrows shows position of proteins expressed following bacterial challenge. The upper band was subsequently identified as defensin.

Fig. 2. SDS-PAGE gel of SepPak separation. Lane1, molecular weight standards; Lane 2, 60\% Acetonitrile/ PBS; Lane 3, 60\% Acetonitrile/ $\mathrm{H}_{2} \mathrm{O}-0.1 \%$ Trifluoroacetic acid (TFA); Lane 4, 15\% Acetonitrile/ PBS; Lane 5, 15\% Acetonitrile / $\mathrm{H}_{2} \mathrm{O}-0.1 \% \mathrm{TFA}$. Arrows indicate the $\sim 5.3 \mathrm{kDa}$ molecular weight band subsequently identified as defensin.

Fig. 3. HPLC C4 chromatogram of Sep-Pak sample. Reverse phase HPLC C4 narrow bore column eluate following injection of the $60 \%$ acetonitrile/ $\mathrm{H}_{2} \mathrm{O}-0.1 \%$ TFA fraction from $D$. variabilis hemolymph. Arrow indicates peak $(7.0 \mathrm{~min})$ coinciding with fraction that had the predominant antimicrobial activity against $B$. subtilis. $\mathrm{MAU}=$ milli-absorbance units.

Fig. 4. HPLC $\mathrm{C}_{18}$ column chromatogram of the previous $\mathrm{C}_{4}$ HPLC 7 min peak. The peak at $\sim 17.0$ min (indicated by the arrow) coincided with the fraction with anti-B. subtilis activity. MAU = milli-absorbance units.

Fig. 5. SDS-PAGE of the $\mathrm{C}_{18}$ column HPLC fraction containing the 17 min peak shown in Fig. 4. Only one distinct band at $\sim 5.3 \mathrm{kDa}$ (arrow) is shown. 
Fig. 6. MALDI-TOF-Mass Spectroscopy of the small peptide (4228.66 Da) from the HPLC ( $\mathrm{C}_{18}$ column) fraction purified from $D$. variabilis hemolymph.

Fig. 7. Experiment to assess the thermostability of tick defensin. Aliquots of purified defensin $(10 \mu \mathrm{l})$ were heated at different temperatures for $30 \mathrm{~min}$, cooled and applied to wells of a tryptic-soy agar plate. Following seeding with a 3-h culture of $B$. subtilis, the plate was incubated overnight $\left(37^{\circ} \mathrm{C}\right)$ and the zones of inhibition measured. Data is the average of two trials.

Fig. 8. Anti-Borrelia activity of tick defensin. Microtiter well inhibition assays were performed with tick defensin alone, and tick defensin plus the addition of $1 \mu \mathrm{g}$ chicken lysozyme. Spirochetes were counted using phase contrast microscopy at 1 hour and 24 hours post incubation. Percent inhibition represents the mean \pm S.D. of Borrelia present after exposure to the proteins versus the mean \pm S.D. present in the Borrelia control. Each data point represents the mean of 3 trials. Error bars represent standard deviation. 
Table 1. Purification of the tick defensin (varisin) from B. burgdorferi-challenged tick (D. variabilis) hemolymph

A. Activity (titer) against B. subtilis

\begin{tabular}{|l|l|c|c|}
\hline \multicolumn{1}{|c|}{ Sample } & $\begin{array}{l}\mu \mathrm{g} / \mu \mathrm{l} \\
\text { protein }\end{array}$ & Titer $^{\mathrm{a}}$ & $\begin{array}{l}\text { Titer } / \\
\mu \mathrm{g} \text { protein }\end{array}$ \\
\hline Whole hemolymph plasma & 44.7 & 8 & 0.18 \\
\hline $15 \%$ ACN/PBS & 28.1 & 8 & 0.29 \\
\hline $60 \%$ ACN/PBS & 4.2 & 4 & 0.95 \\
\hline $15 \%$ ACN/ $\mathrm{H}_{2} \mathrm{O}-0.1 \% \mathrm{TFA}$ & 21.2 & 32 & 1.51 \\
\hline $60 \% \mathrm{ACN} / \mathrm{H}_{2} \mathrm{O}-0.1 \% \mathrm{TFA}$ & 4.5 & 16 & 3.56 \\
\hline
\end{tabular}

average of 3 trials to determine the titer of antimicrobial activity against $B$. subtilis and to calculate average titer of inhibition.

B. Protein purification

\begin{tabular}{|l|l|l|l|l|}
\hline Sample & $\mathrm{mg} / \mathrm{ml}$ & Total protein (mg) & Titer $^{b}$ (avg) & Fold Purification $^{\mathrm{c}}$ \\
\hline Hemolymph Plasma & 44.7 & 84.7 & 8 & 1 \\
\hline $\begin{array}{l}\text { C18 Sep-Pak } \\
\text { (60\% acetonitrile fraction) }\end{array}$ & 4.5 & 5.7 & 16 & 19.9 \\
\hline HPLC C4 narrow bore & 2.8 & 2.3 & 16 & 31.9 \\
\hline HPLC C18 & 0.24 & 0.19 & 26.6 & 619.2 \\
\hline
\end{tabular}

${ }^{b}$ All values represent the average of 3 trials.

c To calculate the level of purification, the ratio of the titer/ protein concentration of the Sep-Pak fraction is divided by the ratio of the titer/protein concentration of whole hemolymph plasma. 